\title{
Mixing Coefficient in Stably Stratified Flows
}

\author{
LAKSHMI KANTHA \\ Department of Aerospace Engineering Sciences, University of Colorado Boulder, Boulder, Colorado \\ Hubert LuCE \\ Université de Toulon, Mediterranean Institute of Oceanography, UM 110, Marseille, France
}

(Manuscript received 12 July 2018, in final form 8 September 2018)

\begin{abstract}
Turbulent mixing in the interior of the oceans is not as well understood as mixing in the oceanic boundary layers. Mixing in the generally stably stratified interior is primarily, although not exclusively, due to intermittent shear instabilities. Part of the energy extracted by the Reynolds stresses acting on the mean shear is expended in increasing the potential energy of the fluid column through a buoyancy flux, while most of it is dissipated. The mixing coefficient $\chi_{m}$, the ratio of the buoyancy flux to the dissipation rate of turbulence kinetic energy $\varepsilon$, is an important parameter, since knowledge of $\chi_{m}$ enables turbulent diffusivities to be inferred. Theory indicates that $\chi_{m}$ must be a function of the gradient Richardson number. Yet, oceanic studies suggest that a value of around 0.2 for $\chi_{m}$ gives turbulent diffusivities that are in good agreement with those inferred from tracer studies. Studies by scientists working with atmospheric radars tend to reinforce these findings but are seldom referenced in oceanographic literature. The goal of this paper is to bring together oceanographic, atmospheric, and laboratory observations related to $\chi_{m}$ and to report on the values deduced from in situ data collected in the lower troposphere by unmanned aerial vehicles, equipped with turbulence sensors and flown in the vicinity of the Middle and Upper Atmosphere (MU) radar in Japan. These observations are consistent with past studies in the oceans, in that a value of around 0.16 for $\chi_{m}$ yields good agreement between $\varepsilon$ derived from turbulent temperature fluctuations using this value and $\varepsilon$ obtained directly from turbulence velocity fluctuations.
\end{abstract}

\section{Introduction}

Apart from the well-mixed turbulent layers adjacent to the air-sea interface and the ground and above the ocean bottom, for the most part, the fluid columns in both the oceans and the atmosphere are stably stratified. As such, turbulent mixing in the interior of the oceans and in the free atmosphere above the atmospheric boundary layer (ABL) occurs under the influence of stable gravitational stratification. The principal mechanism is thought to be flow instability induced by the vertical shear of the horizontal velocity (e.g., Fukao et al. 2011). The Miles-Howard theorem (Miles 1961; Howard 1961) assures flow stability in a two-dimensional, parallel, inviscid shear flow, as long as the gradient Richardson number $\mathrm{Ri}>0.25$ everywhere in the flow. When the local gradient Richardson number falls below a value of approximately 0.25 (e.g., Abarbanel et al. 1984), the

Corresponding author: Lakshmi Kantha, kantha@colorado.edu flow becomes unstable and can give raise to KelvinHelmholtz billows, which mix the fluid, weaken the shear, and restore stability. However, the precise value of the critical Richardson number at which instability ensues is affected by viscosity, by diffusivity (Thorpe et al. 2013), and possibly by background ambient turbulence (Li et al. 2015). Shear instabilities can also be triggered by gravity waves propagating into the interior, which are the principal source of mixing [e.g., the recent review by Tsuda (2014)] in the middle and upper atmosphere $(10-100 \mathrm{~km})$. However, midlevel cloud-base turbulence (Kudo 2013; Kudo et al. 2015) and double-diffusive processes (e.g., Kantha et al. 2011) are exceptions to this rule in the moist troposphere and the oceans, respectively. Both can drive mixing without the need for any vertical shear.

When the fluid is stably stratified, part of the energy input to creating turbulence goes to increase the potential energy of the fluid column through a vertical buoyancy flux. The rest is dissipated. The ratio of the 
buoyancy flux to the dissipation rate of turbulence kinetic energy (TKE) is known as the mixing coefficient $\chi_{m}$. It is difficult to measure the buoyancy flux directly, but knowing the value of $\chi_{m}$ enables the buoyancy flux to be estimated, provided the TKE dissipation rate (per unit mass) $\varepsilon$ is known. The TKE dissipation rate can be readily measured in the ocean using microstructure profilers, but a similar probe has not been available in the atmosphere. As such, there has been more interest among oceanographers than among atmospheric scientists in estimating the mixing coefficient (but see below). While there have been some studies of the mixing coefficient (equivalently, the flux Richardson number $R_{f}$ ) in the atmosphere in the past (e.g., Delage et al. 1997), the availability of inexpensive, autonomous unmanned aerial vehicle (UAV) technology in recent years has enabled in situ measurements of turbulence parameters and, therefore, routine estimation of the mixing coefficient in the atmosphere.

There have been many measurements of the mixing coefficient in the ocean (e.g., Peters et al. 1995; St. Laurent and Schmitt 1999; Arneborg 2002; Mack and Schoeberlein 2004; Holleman et al. 2016). Most observations find its value lies between 0.1 and 0.3 , for the most part, although the scatter is very large. Gregg et al. (2018) have published a comprehensive and authoritative survey recently, and there is no need to repeat their findings here. Instead, the reader is referred to their study and the comprehensive list of references cited therein. While turbulence theory requires the mixing coefficient to be a function of the strength of stable stratification as indicated by the gradient Richardson number $\mathrm{Ri}$, tracer studies on turbulent diffusion in the upper ocean are consistent with the mixing coefficient value of about 0.2 (e.g., Ledwell et al. 1998, 2000, 2004; Gregg et al. 2018). There are other studies reviewed by Peltier and Caulfield (2003) that also offer "compelling" evidence that while the value of the mixing coefficient can be very high during the initial stages of KelvinHelmholtz shear instability (but the degree of mixing can be small), in later stages when the flow truly undergoes transition to turbulence, intense mixing ensues, and the mixing coefficient becomes approximately constant at around 0.2. This result is puzzling. Does it mean that, for some reason, the most likely value of the mixing coefficient in the upper ocean is around 0.2 ? If so, why? These questions need to be addressed. Meanwhile, Gregg et al. (2018) recommend that oceanographers continue using this constant value for the mixing coefficient until related issues can be resolved by further research and gathering observational data in the interior of the oceans.

Turbulent mixing has also been studied in the laboratory (e.g., Thorpe 1973; McEwan 1983; Rohr and Van Atta 1987; Ivey and Imberger 1991; Taylor 1992).
Kantha and Carniel (2009) compare their turbulence model with available laboratory data (from Ohya 2001; Strang and Fernando 2001; Rehmann and Koseff 2004) on the Ri dependence of $R_{f}$ (and therefore indirectly $\chi_{m}$ ). As for numerical simulations of mixing, even with highperformance computers, the salient turbulence Reynolds numbers achievable at present are far less than the values in the oceans and the atmosphere, and this is a major problem in extrapolating those results to realistic Reynolds numbers. For a discussion of laboratory observations and numerical simulations (e.g., Zilitinkevich 2007, 2008), see the nice summary by Gregg et al. (2018).

There have also been some studies of the turbulent mixing coefficient in stably stratified flows by atmospheric scientists, starting with Lilly et al. (1974), who suggested a value of 0.33 corresponding to the upper limit on the flux Richardson number of 0.25 . However, in situ measurements in the atmosphere require specially equipped aircraft and hence were expensive and scarce (e.g., Lilly 1983). This situation has changed, but only recently, by the ready availability of inexpensive UAVs (e.g., Lawrence and Balsley 2013; Kantha et al. 2017).

On the other hand, researchers working with atmospheric radars are very much interested in the value of a particular parameter $\gamma$, which is inversely proportional to the mixing coefficient $\chi_{m}$ (see section 2), because of its importance in deducing atmospheric parameters from radar backscatter data. Alisse and Sidi (2000) and Alisse et al. (2000) determined the value for the mixing coefficient, from high-resolution in situ measurements in the lower stratosphere to the upper troposphere, to be $0.12 \pm 0.06$. From high-resolution radar measurements in the lower troposphere, Dole et al. (2001) found it to be $0.2 \pm 0.1$, whereas high-resolution radar measurements of Wilson et al. (2005) found a median value of 0.16 . These observations tend to reinforce the findings of oceanographers. However, a nice review by Hocking (1999) points out that the Ri dependence of $\gamma$ and hence the mixing coefficient was mostly ignored in the radar literature (e.g., VanZandt et al. 1978, 1981; Gage et al. 1980; Hocking 1985; Thrane et al. 1985, 1987; Lübken 1992; Lübken et al. 1987; Blix et al. 1990), although some studies such as Ottersten (1969), Crane (1980), Gossard and Strauch (1983), Gossard (1990), Gossard et al. (1982, 1984, 1985), Hocking (1992), Blix (1993), Hocking (1996), Hocking and Mu (1997), and Hocking (1999) have acknowledged the Ri dependence of the parameter $\gamma$ and hence $\chi_{m}$. In any case, studies by atmospheric radar scientists have seldom been referenced in oceanic studies, although radar scientists often reference oceanic studies (e.g., Hocking 1999).

From all of these past studies, it is fair to conclude that even though scatter is large, the value of the mixing coefficient in both the oceans and the atmosphere 
appears to lie mostly between values of 0.1 and 0.3 . However, more often than not, the gradient Richardson number $\mathrm{Ri}$ associated with the observed values of the mixing coefficient is not measured and hence remains unknown [see the review by Gregg et al. (2018)]. Consequently, most of these studies cannot shed light on the issue of Ri dependence of $\chi_{m}$ or why a value of around 0.2 yields acceptable diffusivities. It is our intent to present in situ data in the lower troposphere collected at the Middle and Upper Atmosphere (MU) radar observatory in Shigaraki, Japan, during a 2016 field campaign to supplement past studies in the oceans and the laboratory and to provide additional data, which are from the atmosphere and hence independent of oceanic studies. We found that the mixing coefficient in the lower troposphere under stably stratified conditions has a lognormal distribution with the peak at a value of about 0.16 . This value is not equal to but is within $80 \%$ of the abovementioned value of 0.2 , suggesting that perhaps in both the oceans and the atmosphere, the most likely value for the mixing coefficient is around $0.16-0.20$. We also elaborate on the Ri dependence of $\chi_{m}$ and speculate on why assuming a constant $\chi_{m}$ value of somewhere between 0.16 and 0.20 might be a good approximation in the interiors of the oceans and the atmosphere under stably stratified conditions. In section 2, we provide a brief review of the governing equations for potential use by oceanographers unfamiliar with radar terminology and to prevent confusion related to disparate notations used in different fields. Section 3 presents observations, and section 4 provides concluding remarks.

\section{Governing equations}

We start with the equation for the rate of change of TKE:

$$
d(\mathrm{TKE}) / d t=P_{S}+F_{b}-\varepsilon,
$$

where

$$
P_{S}=\left(-\overline{u w} \frac{\partial U}{\partial z}-\overline{v w} \frac{\partial V}{\partial z}\right)
$$

is the rate of TKE production by Reynolds stresses acting on the mean vertical shear,

$$
F_{b}=\frac{g}{\Theta} \overline{w \theta}
$$

is the buoyancy flux, and $\varepsilon$ is the dissipation rate. Here, $U$ and $V$ are velocity components in the $x$ and $y$ directions and $\Theta$ is the mean potential temperature. For turbulence in equilibrium,

$$
P_{S}+F_{b}-\varepsilon=\left(-\overline{u w} \frac{\partial U}{\partial z}-\overline{v w} \frac{\partial V}{\partial z}\right)+\frac{g}{\Theta} \overline{w \theta}-\varepsilon=0 .
$$

Shear production is always positive and hence a source of TKE. The buoyancy flux is positive and hence a source of TKE during convection, but under stable stratification it is negative and is hence a sink of TKE. Dissipation is always a sink. We can write

$$
-\overline{u w}=K_{M} \frac{\partial U}{\partial z}, \quad-\overline{v w}=K_{M} \frac{\partial V}{\partial z}, \quad \text { and } \quad-\overline{w \theta}=K_{\theta} \frac{\partial \Theta}{\partial z},
$$

where $K_{M}$ and $K_{\theta}$ are coefficients of mixing of momentum and heat, respectively, so that

$$
F_{b}=-K_{\theta} N^{2} .
$$

Equation (1) can also be written as

$$
K_{M} S^{2}-K_{\theta} N^{2}-\varepsilon=0,
$$

with

$$
S^{2}=\left(\frac{\partial U}{\partial z}\right)^{2}+\left(\frac{\partial V}{\partial z}\right)^{2}
$$

being the square of the shear frequency $S$ and

$$
N^{2}=\frac{g}{\Theta}\left(\frac{\partial \Theta}{\partial z}\right)
$$

being the square of the buoyancy frequency $N$. The ratio

$$
\mathrm{Ri}=N^{2} / S^{2}
$$

is the gradient Richardson number and is indicative of the degree of static stability of the fluid column. For $\mathrm{Ri}>0$, the column is stably stratified; for $\mathrm{Ri}<0$, it is unstably stratified. The ratio of the buoyancy flux to shear production is the flux Richardson number:

$$
R_{f}=-F_{b} / P_{S} .
$$

By using Eq. (11) to replace $P_{S}$ in Eq. (4),

$$
-F_{b}=\left(\frac{R_{f}}{1-R_{f}}\right) \varepsilon=\chi_{m} \varepsilon,
$$

where

$$
\chi_{m}=-\frac{F_{b}}{\varepsilon}=\frac{R_{f}}{1-R_{f}}
$$


is the ratio of the absolute value of the buoyancy flux to the dissipation rate. The term $\chi_{m}$ is the so-called mixing coefficient, even though it is widely known as the mixing efficiency in oceanic turbulence literature (the ratio of buoyancy flux to shear production $R_{f}$ is the true mixing efficiency). Because the flux Richardson number $R_{f}$ is a function of the gradient Richardson number $\mathrm{Ri}$, the mixing coefficient $\chi_{m}$ must also be a function of Ri.

The buoyancy flux increases the potential energy of the fluid column; therefore, how much of the energy input into turbulence goes to increase the potential energy has always been of interest to oceanographers. However, shear production and buoyancy flux are hard to measure both in the oceans and in the atmosphere, whereas measurement of $\varepsilon$ in the ocean is relatively straightforward using microstructure profilers. Therefore, a quantity of great interest to oceanographers is the mixing coefficient $\chi_{m}$.

Microstructure profilers are free-falling, torpedoshaped objects deployed from stationary ships and carry airfoil probes in the nose whose lateral deflections can be readily measured using piezoelectric sensors. Using a series of assumptions, especially on the shape of the turbulence shear spectrum, these measurements can be translated into estimates of $\varepsilon$ (e.g., Carniel et al. 2012). The profilers also carry sensors to measure temperature, salinity, and pressure. High-frequency-response thermistors enable the dissipation rate $\chi_{T}$ of temperature variance also to be inferred. These profilers have been developed and refined over the past few decades and are now routinely deployed in the global oceans to measure TKE dissipation rates.

In turbulence studies, it is traditional to define structure functions for various quantities. For potential temperature more appropriate to atmospheric flows, the structure function is

$$
D_{\theta}(r)=\left\langle[\Theta(x+r)-\Theta(x)]^{2}\right\rangle .
$$

In the inertial subrange of the turbulence spectrum,

$$
D_{\theta}(r)=C_{\theta}^{2} r^{2 / 3},
$$

where $C_{\theta}^{2}$ is the structure-function parameter for potential temperature and is a measure of the potential energy fluctuations.

The rate of change of potential temperature variance $\overline{\theta^{2}}$ is given by

$$
\frac{d}{d t}\left(\overline{\theta^{2}}\right)=2\left(P_{\theta}-\chi_{\theta}\right)
$$

where

$$
P_{\theta}=-\overline{w \theta}(d \Theta / d z)
$$

is the rate of production of potential temperature variance and $\chi_{\theta}$ is its dissipation rate. For turbulence in equilibrium,

$$
-\overline{w \theta}(\partial \Theta / \partial z)=\chi_{\theta}
$$

so that

$$
\chi_{\theta}=K_{\theta}(d \Theta / d z)^{2} .
$$

From Eqs. (6) and (13),

$$
K_{\theta}=\chi_{m} \varepsilon / N^{2},
$$

and therefore the mixing coefficient is

$$
\chi_{m}=\frac{\chi_{\theta} N^{2}}{\varepsilon(d \Theta / d z)^{2}} .
$$

Because all of the quantities on the rhs of Eq. (19) can be measured by microstructure profilers, the mixing coefficient is readily estimated in the oceans. From Eqs. (9) and (20),

$$
\chi_{\theta}=K_{\theta}\left(\frac{\Theta N^{2}}{g}\right)^{2} .
$$

Now, the one-dimensional potential temperature spectrum in the inertial subrange can be written in terms of either $\chi_{\theta}$ or $C_{\theta}^{2}$ as

$$
S_{\theta}(k)=\beta \varepsilon^{-1 / 3} \chi_{\theta} k^{-5 / 3}=\alpha C_{\theta}^{2} k^{-5 / 3},
$$

where $\alpha \approx 0.25$ and $\beta \approx 0.75-1.0$, although a value of 0.8 is more commonly used. From Eq. (23), it is easy to see that

$$
C_{\theta}^{2}=B_{\theta} \varepsilon^{-1 / 3} \chi_{\theta} ; \quad B_{\theta}=\beta / \alpha .
$$

By using Eq. (24) to replace $\chi_{\theta}$ by $C_{\theta}^{2}$ in Eq. (22),

$$
K_{\theta}\left(\frac{\Theta N^{2}}{g}\right)^{2}=\left(\frac{C_{\theta}^{2}}{B_{\theta}}\right) \varepsilon^{1 / 3} .
$$

By using Eq. (20) then to substitute for $K_{\theta}$,

$$
\varepsilon=\left(\frac{C_{\theta}^{2} g^{2}}{B_{\theta} \chi_{m} \Theta^{2} N^{2}}\right)^{3 / 2}=\left(\frac{\gamma C_{\theta}^{2} g^{2}}{\Theta^{2} N^{2}}\right)^{3 / 2},
$$

where

$$
\gamma=\left(B_{\theta} \chi_{m}\right)^{-1}
$$

is the parameter widely used in radar literature (e.g., Hocking 1999). Therefore, measured values of $C_{\theta}^{2}$ can 
be used to estimate the TKE dissipation rate $\varepsilon$ from Eq. (26), or equivalently, if $\varepsilon$ and $C_{\theta}^{2}$ are known, $\gamma$ and the mixing coefficient $\chi_{m}$ can be determined.

The flux Richardson number [Eq. (11)] can also be written as

$$
R_{f}=\frac{K_{\theta}}{K_{M}}\left(\frac{N^{2}}{S^{2}}\right)=\operatorname{Ri}\left(\frac{K_{\theta}}{K_{M}}\right)=\frac{\mathrm{Ri}}{\operatorname{Pr}_{t}}
$$

where

$$
\operatorname{Pr}_{t}=K_{M} / K_{\theta}
$$

is the turbulent Prandtl number, so that $\gamma$ can also be written as

$$
\gamma=\frac{\left(\operatorname{Pr}_{t}-R i\right)}{B_{\theta} R i} .
$$

By using the identity

$$
\operatorname{Pr}_{t}=\mathrm{Ri} / R_{f}
$$

in Eq. (30),

$$
\gamma=\frac{1}{B_{\theta}}\left(\frac{1-R_{f}}{R_{f}}\right)=\frac{1}{B_{\theta} \chi_{m}} .
$$

Thus $\gamma$ is inversely proportional to the mixing coefficient $\chi_{m}$, and vice versa:

$$
\chi_{m}=\left(B_{\theta} \gamma\right)^{-1},
$$

with $B_{\theta}$ having values between 3 and 4 , with the most commonly used value being 3.2 (e.g., Gossard et al. 1982, 1984). Note that

$$
R_{f}=\frac{\chi_{m}}{1+\chi_{m}} .
$$

Using second-moment closure of turbulence, Kantha (2003) and Kantha and Carniel (2009) have obtained $R_{f}$ as a function of $\mathrm{Ri}$ in stably stratified flows. These results can be approximated very well (see Figs. 6 and 7 below) by the empirical expression

$$
R_{f}=R_{f}^{\max }\left[1-\exp \left(-\frac{\mathrm{Ri}}{R_{f}^{\max \operatorname{Pr}_{t}^{0}}}\right)\right],
$$

where $R_{f}^{\max }$ is the maximum flux Richardson number in the limit $\mathrm{Ri} \rightarrow \infty$, and $\operatorname{Pr}_{t}^{0}$ is the Prandtl number at $\mathrm{Ri}=$ 0 (neutrally stratified flows). Equations (33)-(35) can then be used to compute $\chi_{m}$ and hence $\gamma$ from measured values of Ri. As a corollary, Ri can be determined (if unknown) from Eqs. (33)-(35) from values of $\gamma$ inferred from simultaneous measurements of $\varepsilon$ and $C_{\theta}^{2}$ using Eq. (24). By using Eqs. (31) and (35), $\operatorname{Pr}_{t}$ can be related to $\mathrm{Ri}$ by the equation

$$
\frac{1}{\mathrm{Pr}_{t}}=\frac{R_{f}^{\max }}{\mathrm{Ri}}\left[1-\exp \left(-\frac{\mathrm{Ri}}{R_{f}^{\max \operatorname{Pr}_{t}^{0}}}\right)\right] .
$$

In situ measurements of temperature are often used in many studies, and the structure-function parameter of temperature in the inertial subrange is then defined as

$$
D_{T}(r)=C_{T}^{2} r^{2 / 3},
$$

where

$$
D_{T}(r)=\left\langle[T(x+r)-T(x)]^{2}\right\rangle .
$$

Also, from Tatarskii (1961),

$$
\chi_{T}=K_{T}\left(\frac{d T}{d z}+\Gamma_{a}\right)^{2}=K_{T}\left(\frac{T}{\Theta} \frac{d \Theta}{d z}\right)^{2}
$$

and

$$
C_{T}^{2}=B_{T} \varepsilon^{-1 / 3} \chi_{T},
$$

so that by using Eq. (20)

$$
\begin{aligned}
\varepsilon & =\left\{\left(\frac{K_{\theta}}{K_{T}}\right)\left(\frac{B_{\theta}}{B_{T}}\right)\left[\frac{C_{T}^{2} N^{2} \Theta^{2}}{B_{\theta} \chi_{m} T^{2}(d \Theta / d z)^{2}}\right]\right\}^{3 / 2} \\
& =\left(\frac{\gamma C_{T}^{2} g^{2}}{T^{2} N^{2}}\right)^{3 / 2} .
\end{aligned}
$$

Radar signals are backscattered from refractive index fluctuations in the atmosphere, and so it is common to use turbulence parameters based on fluctuations in the refractive index $n$, assuming inertial subrange:

$$
D_{n}(r)=C_{n}^{2} r^{2 / 3}
$$

where

$$
\begin{aligned}
D_{n}(r) & =\left\langle[n(x+r)-n(x)]^{2}\right\rangle, \\
\chi_{n} & =K_{n}(d n / d z)^{2}=K_{n} M^{2},
\end{aligned}
$$

and

$$
C_{n}^{2}=B_{n} \varepsilon^{-1 / 3} \chi_{n}
$$

so that, by using (20), 


$$
\varepsilon=\left\{\left(\frac{K_{\theta}}{K_{n}}\right)\left(\frac{B_{\theta}}{B_{n}}\right)\left[\frac{C_{n}^{2} N^{2}}{B_{\theta} \chi_{m}(d n / d z)^{2}}\right]\right\}^{3 / 2}=\left(\frac{\gamma C_{n}^{2} N^{2}}{M^{2}}\right)^{3 / 2} .
$$

Equations (46) and (41) or Eq. (26) can be used to estimate $\gamma$ and hence $\chi_{m}$.

Although this study is focused on stably stratified flows, convective turbulence is also of great interest in both the atmosphere and the oceans, for which Eqs. (2) and (16) yield

$$
\chi_{m}=-1
$$

since shear production $P_{S}=0$. Substituting for $\chi_{m}$ in Eq. (41), we get

$$
\varepsilon=\left[\frac{C_{T}^{2} g^{2}}{B_{\theta} T^{2}\left(-N^{2}\right)}\right]^{3 / 2} .
$$

Note that $N^{2}<0$ in a convective layer.

\section{ShUREX 2016 observations}

The Shigaraki MU radar observatory (Fukao et al. 1985a,b), run by the Research Institute for Sustainable Humanosphere of the Kyoto University in Japan, is located in Shigaraki $\left(34.854061^{\circ} \mathrm{N}, 136.105606^{\circ} \mathrm{E}\right)$ at a height of $378 \mathrm{~m}$ above sea level (MSL). It consists of a variety of instruments for measuring and monitoring the atmospheric column, the principal one being the 103-m-diameter, 46.5-MHz MU radar. During the Shigaraki UAV-Radar Experiment (ShUREX) campaigns at the Shigaraki observatory, turbulence sensors deployed on DataHawk UAVs, which were developed at the University of Colorado by D. Lawrence (Lawrence and Balsley 2013), were flown in the immediate vicinity of the MU radar to obtain in situ measurements of turbulence parameters near the radar (see Kantha et al. 2017). A high-frequency-response Pitot tube system was used to measure velocity fluctuations, from which the TKE spectrum was deduced and used to estimate the TKE dissipation rate $\varepsilon$. Temperature fluctuations were also measured using a high-frequency-response $(800 \mathrm{~Hz})$ cold-wire sensor and were used to estimate $C_{T}^{2}$. Three ShUREX campaigns were conducted at the observatory during the spring-summer seasons of 2015, 2016, and 2017. A principal goal of these campaigns was to obtain in situ measurements of $\varepsilon$ and $C_{T}^{2}$ in the lower troposphere, guided and supplemented by radar observations so that interesting atmospheric structures could be identified by the radar in near-real time and probed by the UAV. See Kantha et al. (2017) for a more detailed description of ShUREX campaigns, the sensors deployed, and analysis of turbulence data. [See Kantha et al. (2018, manuscript submitted to Earth Planets Space) and Luce et al. (2018, manuscript submitted to Earth Planets Space) for details on extracting turbulence properties from radar backscattered signal.] Hocking et al. (2016) summarize very well the existing state of the art in the use of atmospheric radars for measurements of $3 \mathrm{D}$ velocity field and turbulence in the atmospheric column above the radar.

All of the UAV flights were undertaken from a field roughly $1 \mathrm{~km}$ southeast of the MU radar. For most measurements, the UAV ascended and descended over the field in a spiral path of roughly $100-\mathrm{m}$ diameter at a vertical velocity of about $2 \mathrm{~m} \mathrm{~s}^{-1}$. We will restrict ourselves to the 2016 data for this study. A total of 45 flights were conducted between 21 May and 13 June 2016, of which roughly 16 flights (flights 5, 8, 9, 15, 17, 18, 21, 22, $28,30,31,32,37,38,40$, and 41) yielded useful scientific data. Of these, flights $17,18,21$, and 32 were primarily in the convective boundary layer $(\mathrm{CBL})$ and therefore were not included in this study. The remainder of the flights probed mostly a stably stratified atmospheric column above a shallow CBL, and once again the data inside the $\mathrm{CBL}$ and any convective and cloudy regions in the atmospheric column were excluded from the study.

The stable atmospheric column above the CBL consisted mostly of "sheets and layers" types of structures, although at times, there were imbedded convective structures below the cloud base created by evaporation of ice particles in the dry air layer below the cloud base. Data in these convective regions were discarded. For brevity, we will not describe the data analysis procedures here but instead refer readers to H. Luce (2018, unpublished manuscript).

The sheets-and-layers structures (apparently turbulent layers separated by thin sheetlike regions) were produced by humidity gradients in the presence of water vapor in the atmosphere. The backscattered signal of the VHF radar is especially sensitive to humidity gradients and highlights even small humidity gradients, which appear then as dark sheets (see Fig. 1). As such, these sheets-and-layers structures seen above the CBL in the moist troposphere may not be dynamically significant at all. Turbulence above the CBL is still generated predominantly by shear, as measurements show. Most important, these sheetlike structures are not the same as those seen sometimes in the oceanic thermocline, where they do highlight strong density gradients of dynamical significance.

Figure 1 shows a typical radar image, obtained during UAV flight 5 on 30 May 2016. The fainter line shows the UAV track, and the dark line below it shows the altitude above sea level of the UAV. Near-real-time radar 

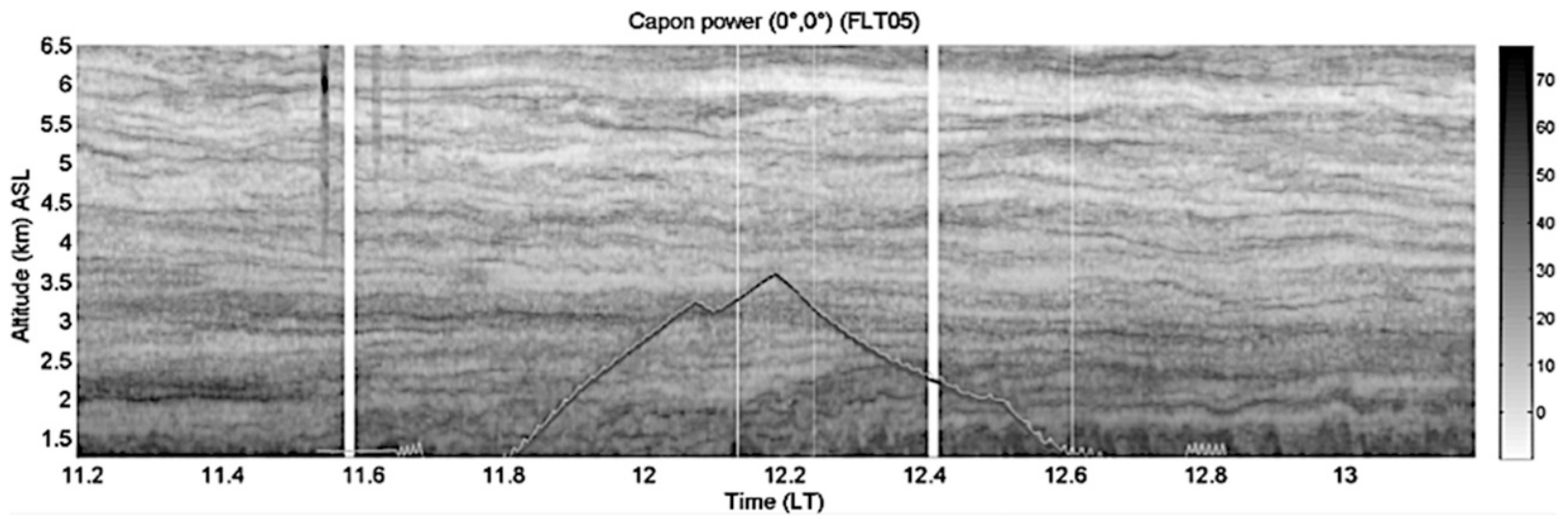

FIG. 1. MU radar image during UAV flight 5 on 30 May 2016. The dark line shows the altitude of the UAV, and the fainter line immediately above it shows the radar track of the UAV (i.e., range) ascending and descending in a spiral pattern.

images like this were very useful for understanding what exactly the UAV was probing and for directing it, if need be, to probe interesting nearby atmospheric structures. The radar can detect structures only above $1.3 \mathrm{~km}$ MSL, and, as can be seen, the ABL height was less than $1.3 \mathrm{~km}$ during UAV ascent but increased to about $1.5 \mathrm{~km}$ MSL during descent. As such, the UAV measured stably stratified regions above roughly $1.5-\mathrm{km}$ MSL altitude.

The left-hand panels of Figs. 2a and 2b show the vertical profiles of $\varepsilon$ (thick blue line) and $C_{T}^{2}$ (thick cyan line) during ascent and descent phases of flight 5 , respectively. The thin black line shows measured $N^{2}$. The extent of the $\mathrm{CBL}$, where properties are relatively more uniform, is shown by a gray rectangle extending from 0 to $1200 \mathrm{~m}$ in Fig. 2a and to $1500 \mathrm{~m}$ in Fig. 2b, consistent with the radar image in Fig. 1. Since the CBL extends to only about $1200 \mathrm{~m}$ MSL during ascent, it cannot be seen in Fig. 1. The atmosphere above the CBL consists of the so-called sheets and layers. The center panels compare $\varepsilon$ measured directly by the UAV with $\varepsilon$ derived from $C_{T}^{2}$ [using Eq. (41)] using measured values of $N^{2}$ (thin black line) and assuming a constant value of 1.95 for $\gamma$ (equivalent to $\chi_{m}$ of 0.16 ). The two track each other very well. The right-hand panels show the same quantities but using a standard value for $N^{2}$ $\left(1.47 \times 10^{-4} \mathrm{~s}^{-2}\right)$ in the troposphere in Eq. (41). The red curve indicates that there is a good agreement between measured $\varepsilon$ (thick blue line) and that derived from $C_{T}^{2}$ (thick red line) in the CBL, if $N^{2}$ is taken as $0.4 \times 10^{-4}$. However, since an $\chi_{m}$ value of 0.16 is used in Eq. (41) but $\chi_{m}=-1$ in the CBL, this is equivalent to $N^{2} \approx-6.4 \times$ $10^{-6} \mathrm{~s}^{-1}$ in the CBL [Eq. (48)].

Figure 3 shows a histogram of the mixing coefficient $\chi_{m}$ obtained from UAV measurements of $\varepsilon$ and $C_{T}^{2}$ [using Eqs. (33) and (41)], plotted in both log and linear scales for all flights. A few data points that fall above the absolute theoretical upper bound of 1.0 have been omitted. The theoretical upper bound of $1 / 3$ from turbulence theory (e.g., Kantha and Carniel 2009) is also shown. The extended vertical lines show that the peak of the distribution occurs at a value of about 0.16 (it is also the median value), close to the value of 0.2 cited in oceanographic literature.

Figure 4 shows a scatterplot of $\varepsilon$ measured directly by the UAV against those derived from $C_{T}^{2}$, assuming a constant value of 1.95 for $\gamma$, equivalent to mixing coefficient $\chi_{m}$ of 0.16 . There is a remarkably tight correlation between the two that appears to justify the use of a constant value of 0.16 for the mixing coefficient in turbulence studies.

Technical difficulties have hindered accurate determination of wind velocities (and hence $\mathrm{Ri}$ ) directly from UAV measurements. The radar itself can infer $\mathrm{Ri}$ only at scales of $150 \mathrm{~m}$ and above. Therefore, we use the value of $\mathrm{Ri}$ determined from radiosondes released during the flights. Only flights $8,15,28$, and 41 are considered, since radiosondes released during the flight were available and stably stratified conditions prevailed over the CBL. Table 1 shows conditions for these flights.

Note that the UAV flights were made $1 \mathrm{~km}$ southwest of the radar and radiosondes were released at the radar site and drifted away from both the radar and the UAV. The ascent rates of the UAV and the radiosonde were not the same. Consequently, there could be a vertical shift in altitude of properties measured by the radiosonde relative to the UAV. Therefore, Ri values were computed from radiosonde data as a function of altitude by locally shifting the radiosonde $N^{2}$ profiles vertically until they matched the $N^{2}$ profiles measured by the UAV. One can therefore expect some scatter in the results, since the radiosonde and the UAV are not measuring the same volume in the atmospheric column. Measurements at Shigaraki have shown a remarkable degree of horizontal homogeneity (except for small vertical shifts, presumably due to wave motions) in properties over scales of 5-10 km 
(a)

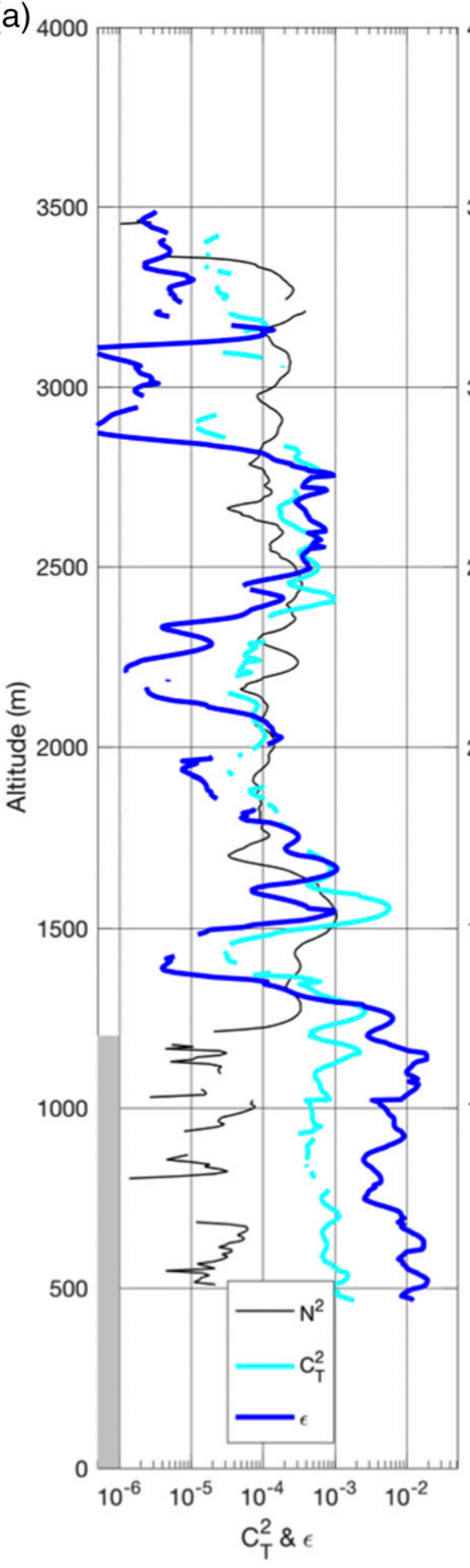

FLT05-A1

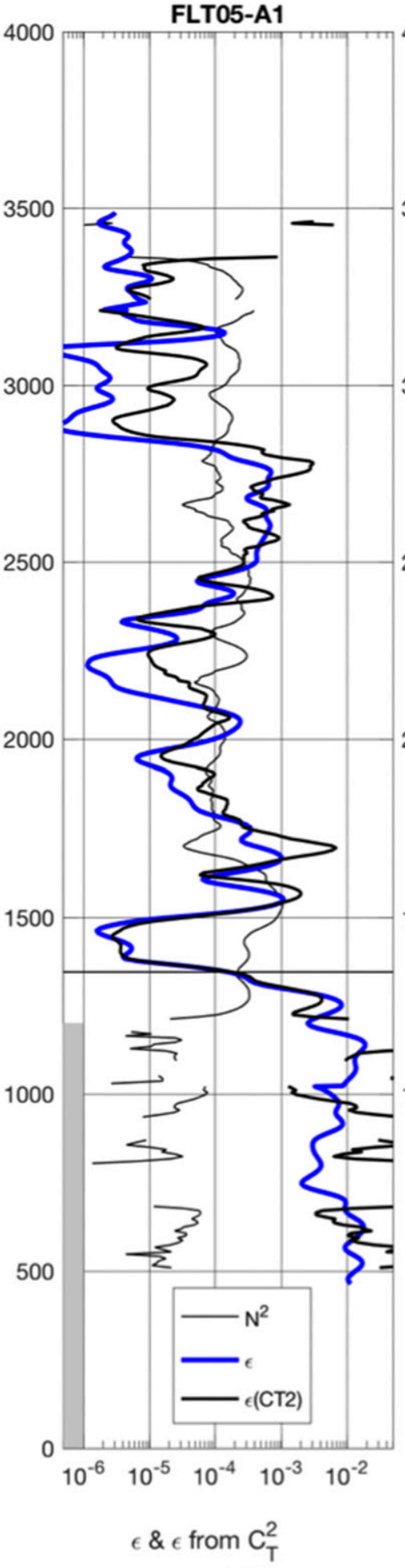

$\gamma=1.95$

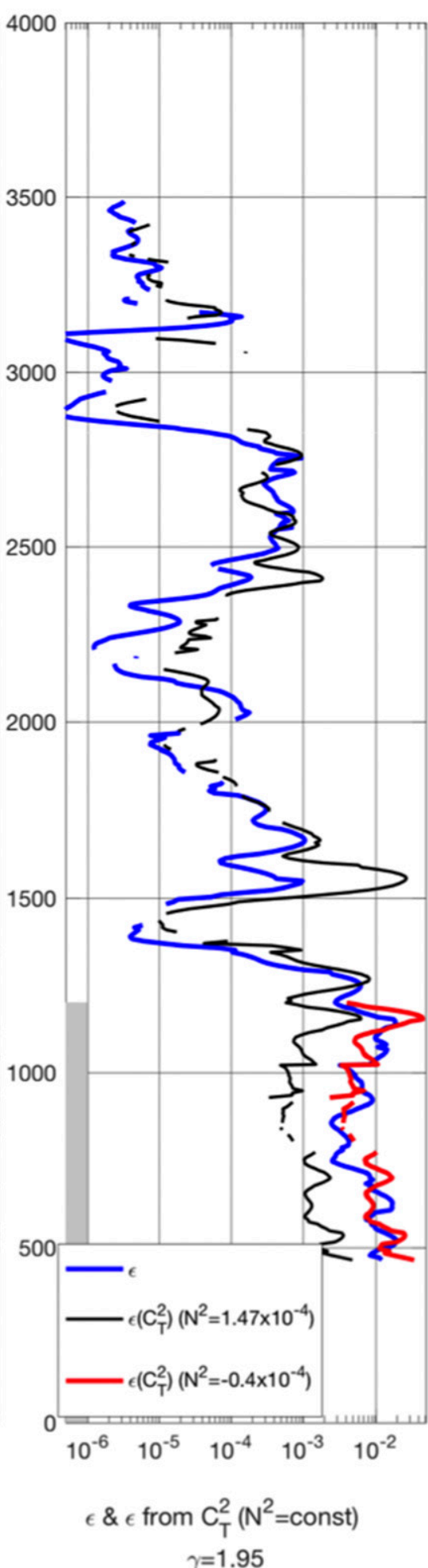

FIG. 2. Vertical profiles of various quantities during the (a) ascent and (b) descent phases of UAV flight 5: (left) profiles of measured values of $\varepsilon$ (thick blue line), $C_{T}^{2}$ (thick cyan line), and $N^{2}$ (thin black line); (center) measured $\varepsilon$ (thick blue line) and $\varepsilon$ derived from $C_{T}^{2}$ (thick black line) using measured values of $N^{2}$ (thin black line) and assuming a constant value of 1.95 for $\gamma$ (equivalently $\chi_{m}$ of 0.16 ); (right) measured $\varepsilon$ (thick blue line) and $\varepsilon$ derived from $C_{T}^{2}$ (thick black and red lines) using constant values for $N^{2}$, assuming constant value of 1.95 for $\gamma$ (equivalently $\chi_{m}$ of 0.16 ). 
(b)

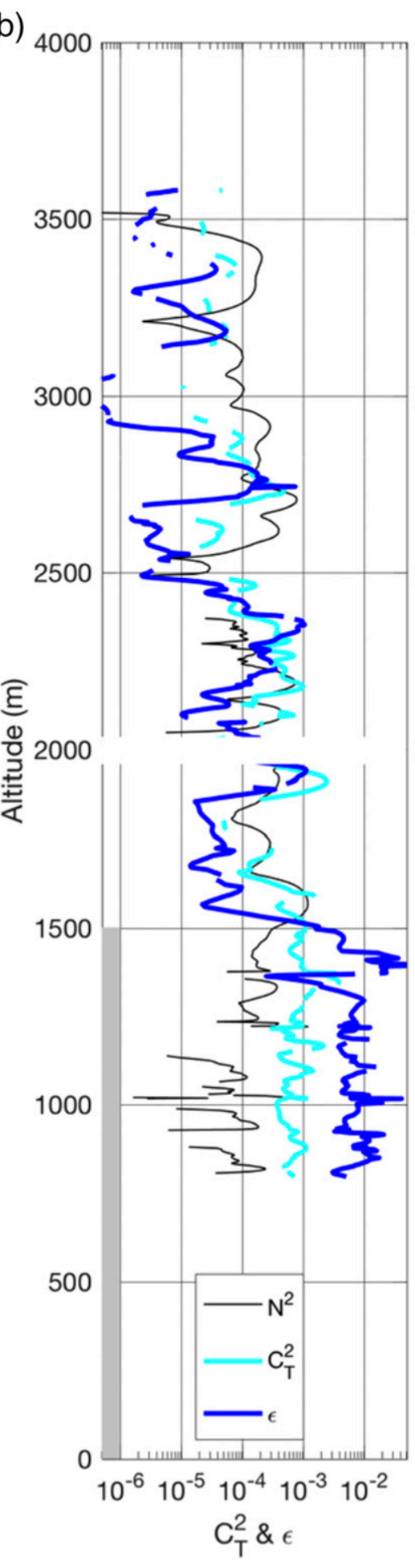

4000 FLT05 D1

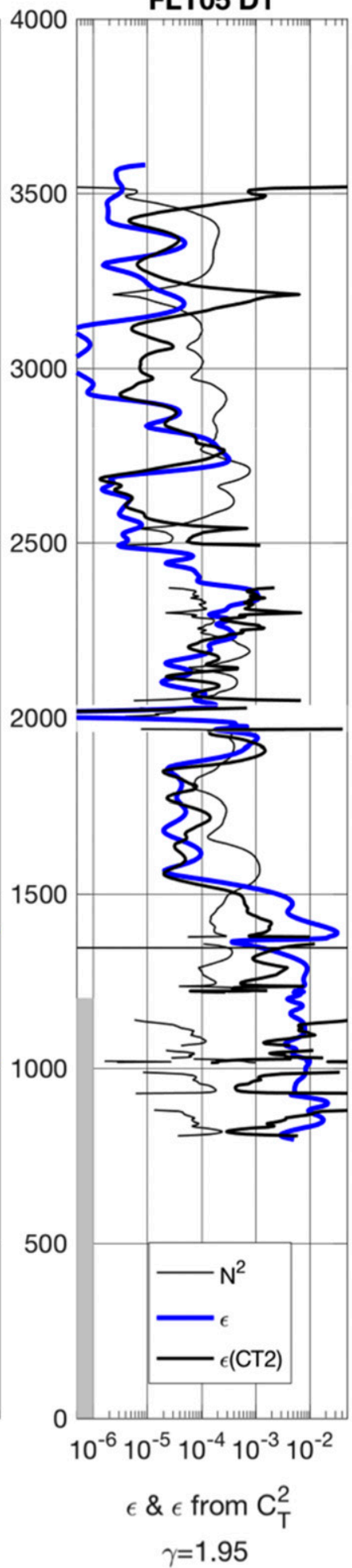

4000

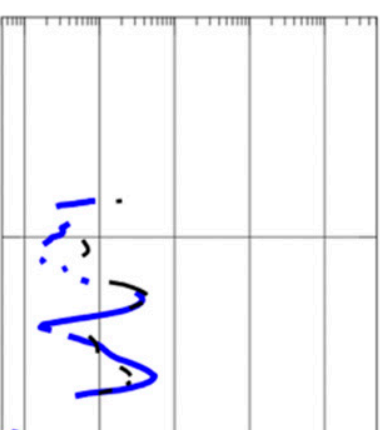

3000 2500

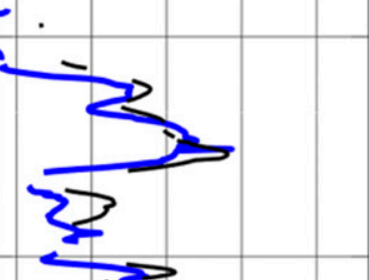

2000

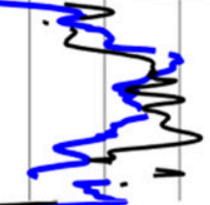

1500

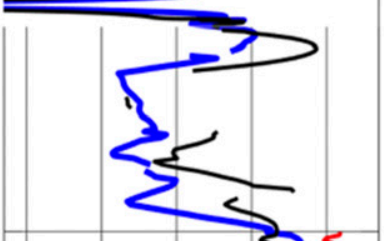

FIG. 2. (Continued)

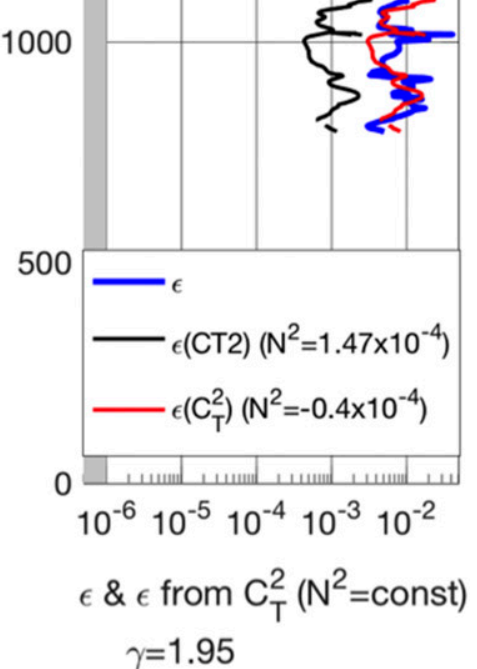



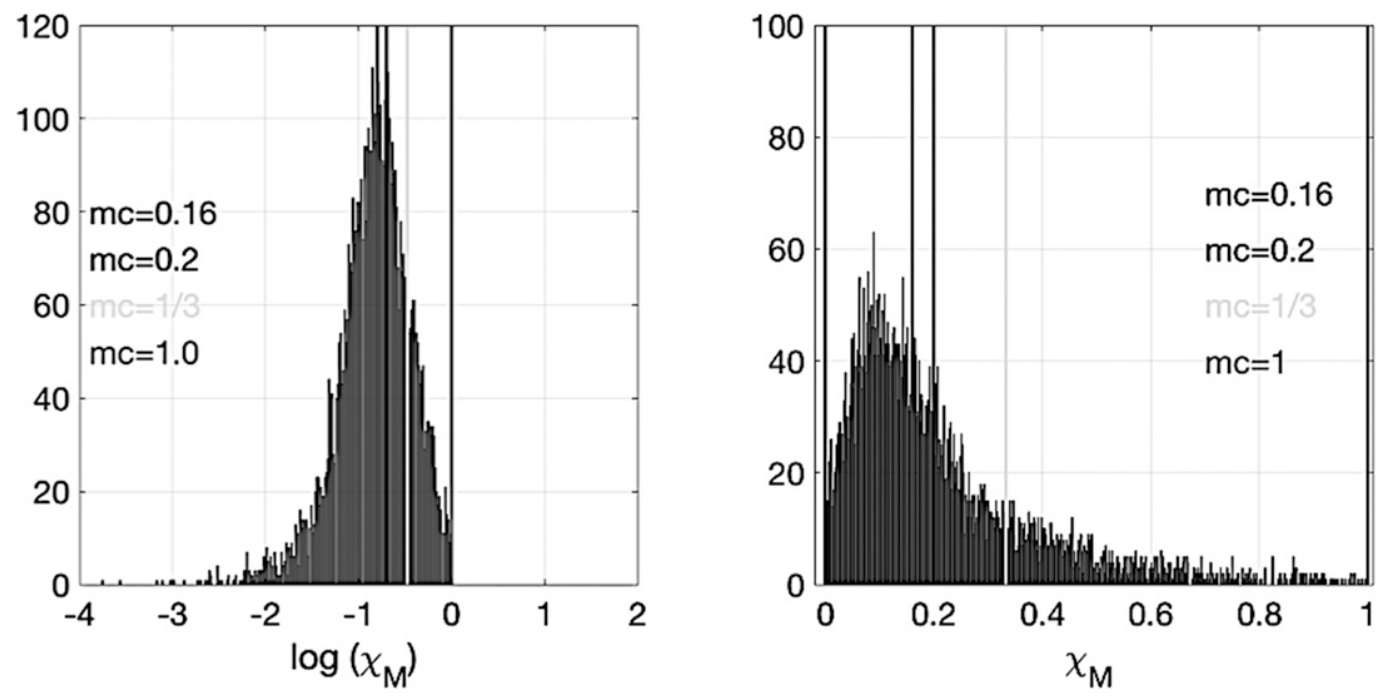

FIG. 3. Histogram of the mixing coefficients $\chi_{m}$ deduced from UAV observations of $\varepsilon$ and $C_{T}^{2}$. From left to right, the vertical lines are for $\chi_{m}=0.16,0.2,0.33$, and 1.0.

(Luce et al. 2018). When Luce et al. (2018) compared radar-measured values with radiosonde-measured values for parameters such as $N^{2}$ and $M^{2}$ (indicative of the gradients of density and humidity), there was remarkable agreement. It appears that the radiosonde and the radar are measuring the same features and, by extension then, the UAV and radiosonde are measuring the same parameters with a slight delay. The estimates of $\mathrm{Ri}$ profiles by the radar and the radiosonde also showed remarkable agreement at all altitudes. Therefore, all three instruments detected the same prominent temperature and humidity gradients, down to decameter scales in stratified conditions. These gradients extended horizontally over a few kilometers at least and persisted for hours without significant changes [see Luce et al. (2018) and Luce et al. (2018, manuscript submitted to Earth Planets Space) for details and measurement errors; see also Balsley et al. (2010) for radiosonde measurements of velocity and $\mathrm{Ri}$.

Measurements of $\varepsilon$ and the local buoyancy frequency $N$ enable the so-called buoyancy Reynolds number

$$
\operatorname{Re}_{b}=\varepsilon /\left(\nu N^{2}\right)
$$

to be extracted from ShUREX observations; $\mathrm{Re}_{b}$ is also called turbulence activity by oceanographers (e.g., Gregg et al. 2018; Gibson 1980), who use it as a measure of the strength of the turbulent mixing. The $\mathrm{Re}_{b}$ can also be written as

$$
\operatorname{Re}_{b}=\left[\frac{\left(\varepsilon / N^{3}\right)^{1 / 2}}{\left(\nu^{3} / \varepsilon\right)^{1 / 4}}\right]^{4 / 3}=\left(\frac{L_{O}}{L_{K}}\right)^{4 / 3} \approx 13.9\left(\frac{L_{\text {outer }}}{L_{\text {inner }}}\right)^{4 / 3},
$$

where $L_{O}$ is the Ozmidov scale, which denotes the outer scale of turbulence $L_{\text {outer }}$, and $L_{K}$ denotes the Kolmogoroff viscous scale, which is proportional to the inner scale of turbulence $L_{\text {inner }}\left[\sim(7.2-12.4) L_{K}\right]$. The inner and outer scales delimit the Kolmogoroff inertial subrange (ISR) of turbulence kinetic energy spectrum, where turbulence is expected to be isotropic. The ratio of the two scales,

$$
R=L_{\text {outer }} / L_{\text {inner }},
$$

is a measure of how well developed turbulence is. The $\mathrm{Re}_{b}$ is related to $R$ by

$$
\operatorname{Re}_{b}=13.9 R^{4 / 3} .
$$

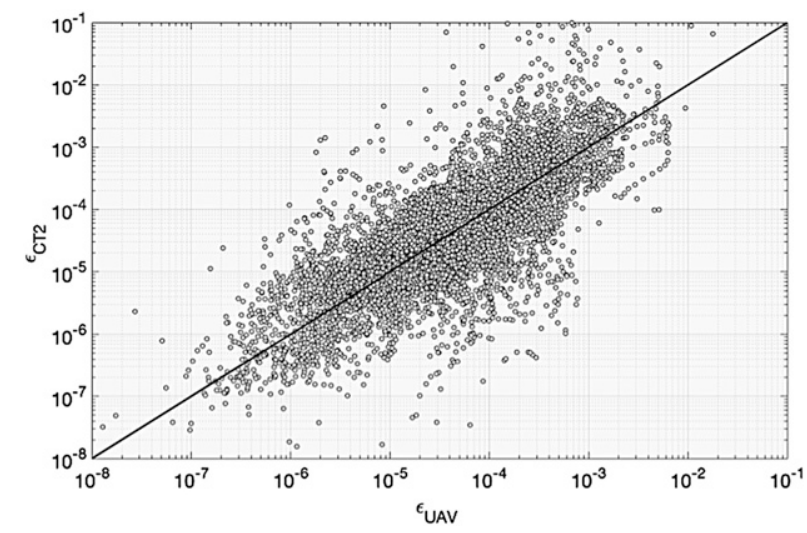

FIG. 4. Scatterplot of $\varepsilon$ derived from $C_{T}^{2}$ measurements, assuming a $\gamma$ value of 1.95 , against those measured directly by the Pitot sensor. 
TABLE 1. A list of UAV flights during which radiosondes were released from the MU radar site. Data from these flights are used in the study.

\begin{tabular}{cccccc}
\hline \hline Flight No. & Date & $\begin{array}{c}\text { Launch time for } \\
\text { UAV (LT) }\end{array}$ & $\begin{array}{c}\text { Launch time for } \\
\text { radiosonde (LT) }\end{array}$ & $\begin{array}{c}\text { Flight duration for } \\
\text { UAV (min) }\end{array}$ & $\begin{array}{c}\text { Max. alt for } \\
\text { UAV (km) }\end{array}$ \\
\hline 8 & 28 May & $1110: 37$ & $1205: 00$ & 81 & 4.0 \\
15 & 30 May & $1434: 43$ & $1458: 00$ & 80 & 4.0 \\
28 & 8 Jun & $0941: 28$ & $1013: 00$ & 99 & 4.0 \\
41 & 13 Jun & $1410: 10$ & $1420: 54$ & 90 & 4.5 \\
\hline
\end{tabular}

Therefore, $\mathrm{Re}_{b}$ is, in strict terms, not the turbulence Reynolds number but more appropriately is a measure of the broadness of the ISR. For turbulence to be well established, $R$ must have a value of at least 2 , and therefore $\mathrm{Re}_{b}$ must be above 35 . Oceanographers dealing with doublediffusive mixing often use the value of 25 as the upper limit of that type of mixing. For $R=10$ (one decade of ISR in the turbulence spectrum), $\mathrm{Re}_{b} \approx 300$; for $R=1000$ (three decades), $\operatorname{Re}_{b} \approx 1.4 \times 10^{5}$. Typical observations of $\mathrm{Re}_{b}$ in the interior of the oceans (see Gregg et al. 2018) show that the ISR extends to between one and three decades in the TKE spectrum (Peters et al. 1995, their Fig. 10).

Figure 5 shows $\mathrm{Re}_{b}$ plotted against Ri from ShUREX 2016 observations. The values lie mostly between $10^{2}$ and $10^{6}$. The upper value corresponds to scale ratio $R$ of 2275 , indicating that in the lower troposphere the ISR can extend over three decades in the TKE spectrum.

Figures $6 \mathrm{a}$ and $6 \mathrm{~b}$ respectively show $1 / \operatorname{Pr}_{t}$ and $\operatorname{Pr}_{t}$ plotted against $\mathrm{Ri}$. The two panels present the same information but in two different formats. Figure 7a uses the log-linear scale format for easier comparison with Hocking and $\mathrm{Mu}$ (1997), which is popular among radar scientists, whereas Fig. $7 \mathrm{~b}$ uses the $\log -\log$ format that is compatible with Canuto et al. (2008) and Kantha and Carniel (2009), which is familiar to atmospheric scientists and oceanographers. The cyan circles denote ShUREX 2016 observations. Blue circles are from laboratory experiments (Strang and Fernando 2001; Ohya 2001; Rehmann and Koseff 2004), direct-numerical-simulation numerical-model results of Stretch et al. (2001), and large-eddy-simulation model results of Zilitinkevich et al. (2007, 2008), as presented in Canuto et al. (2008) and Kantha and Carniel (2009). Red circles are from observations in the atmosphere (Kondo et al. 1978; Gossard and Frisch 1987; Bertin et al. 1997).

It can be seen that ShUREX observations (cyan circles) are in good agreement with the earlier studies. The large scatter seen is typical of measurements such as these (see large circles from earlier studies, exhibiting a similar degree of scatter). The thin red line corresponds to

$$
\operatorname{Pr}_{t}^{-1}=(3.6 \mathrm{Ri})^{-1}
$$

as in Gossard and Frisch (1987). The thin black line corresponds to

$$
\operatorname{Pr}_{t}^{-1}=\left[\left(1+B_{\theta} \gamma\right) \mathrm{Ri}\right]^{-1},
$$

with a constant value for $\gamma$ of 1.95. From Eq. (36), it can be seen that

$$
\operatorname{Pr}_{t}^{-1} \rightarrow \frac{R_{f}^{\max }}{\mathrm{Ri}} \quad \text { as } \quad \mathrm{Ri} \rightarrow \infty
$$

so that Eqs. (53) and (54) are equivalent to assuming $\mathrm{Ri}$ is large and $R_{f}^{\max }=0.28$ and 0.14 , respectively. Although the scatter in observational data is large, Eq. (54) is

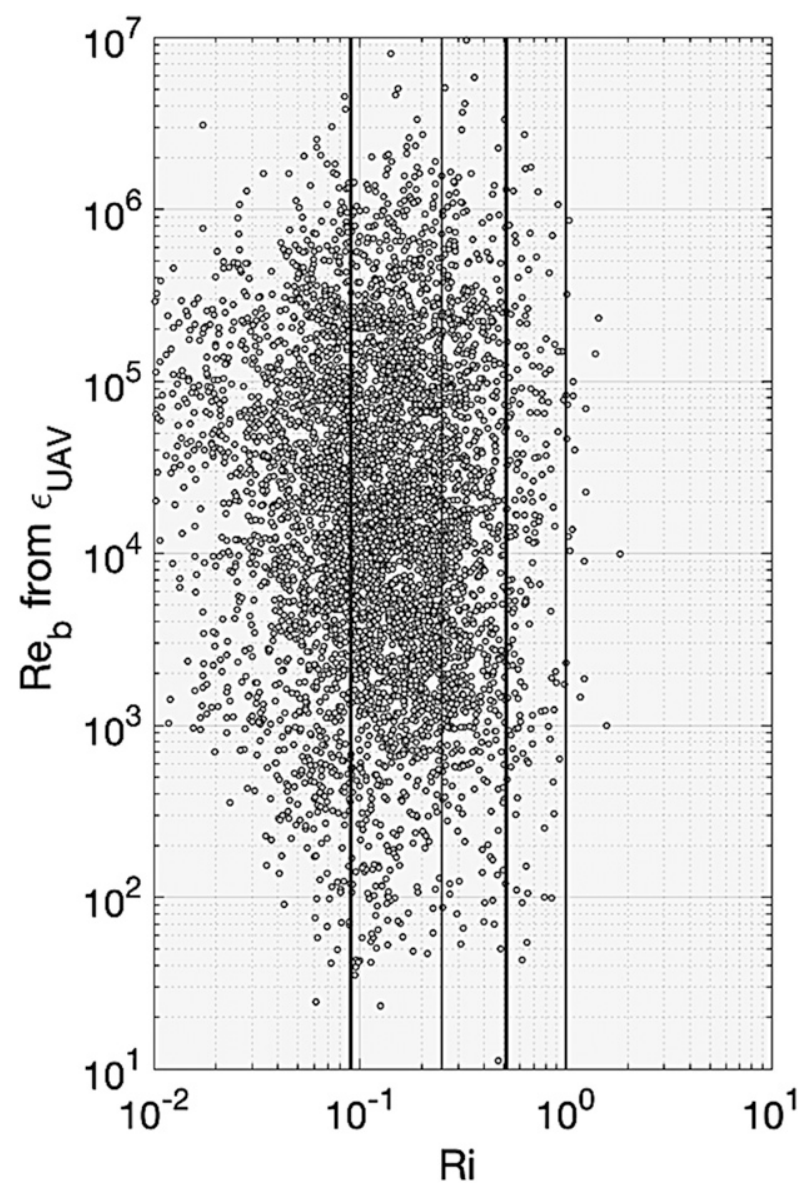

FIG. 5. Turbulence activity (also known as "buoyancy Reynolds number") plotted against gradient Richardson number Ri. From left to right, the vertical lines are for $\mathrm{Ri}=0.09,0.25,0.5$, and 1.0. 
(a)
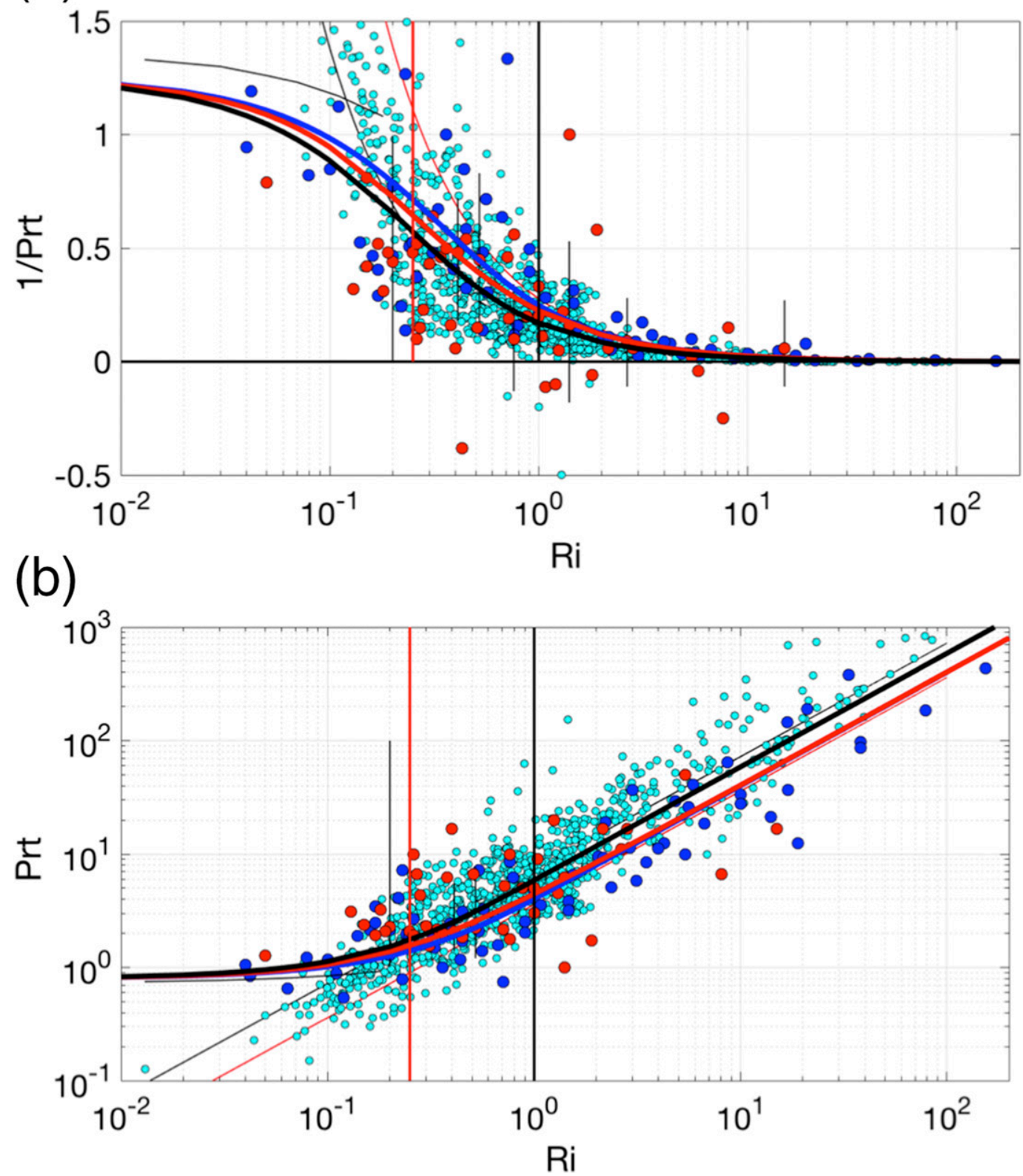

FIG. 6. (a) Inverse of the Prandtl number plotted against gradient Richardson number. See the text for details. The plot uses the log-linear scale format of Hocking and Mu (1997) for easier comparison. Cyan circles denote ShUREX 2016 measurements. Large blue circles show data from earlier studies in the laboratory and numerical simulations. Large red circles show measurements in the atmosphere. For more details, see the text. The thick blue and black lines correspond to the semiempirical law of Eq. (36), whereas the thick red line corresponds to the second-moment closure model of Kantha and Carniel (2009). Thin red and black lines correspond to Eqs. (53) and (54). The thin black line at the top corresponds to Businger et al. (1971). (b) As in (a), but for the Prandtl number plotted against gradient Richardson number using the log-log scale format of Canuto et al. (2008) and Kantha and Carniel (2009) for easier comparison.

consistent with observational data as long as Ri values are higher than approximately 0.25 . However, both Eqs. (53) and (54) do not behave well at Ri values below about 0.25 , yielding Prandtl numbers well below a value of unity. It is well known from numerous laboratory experiments that in neutrally stratified turbulent flows $(\mathrm{Ri}=0)$ the Prandtl 

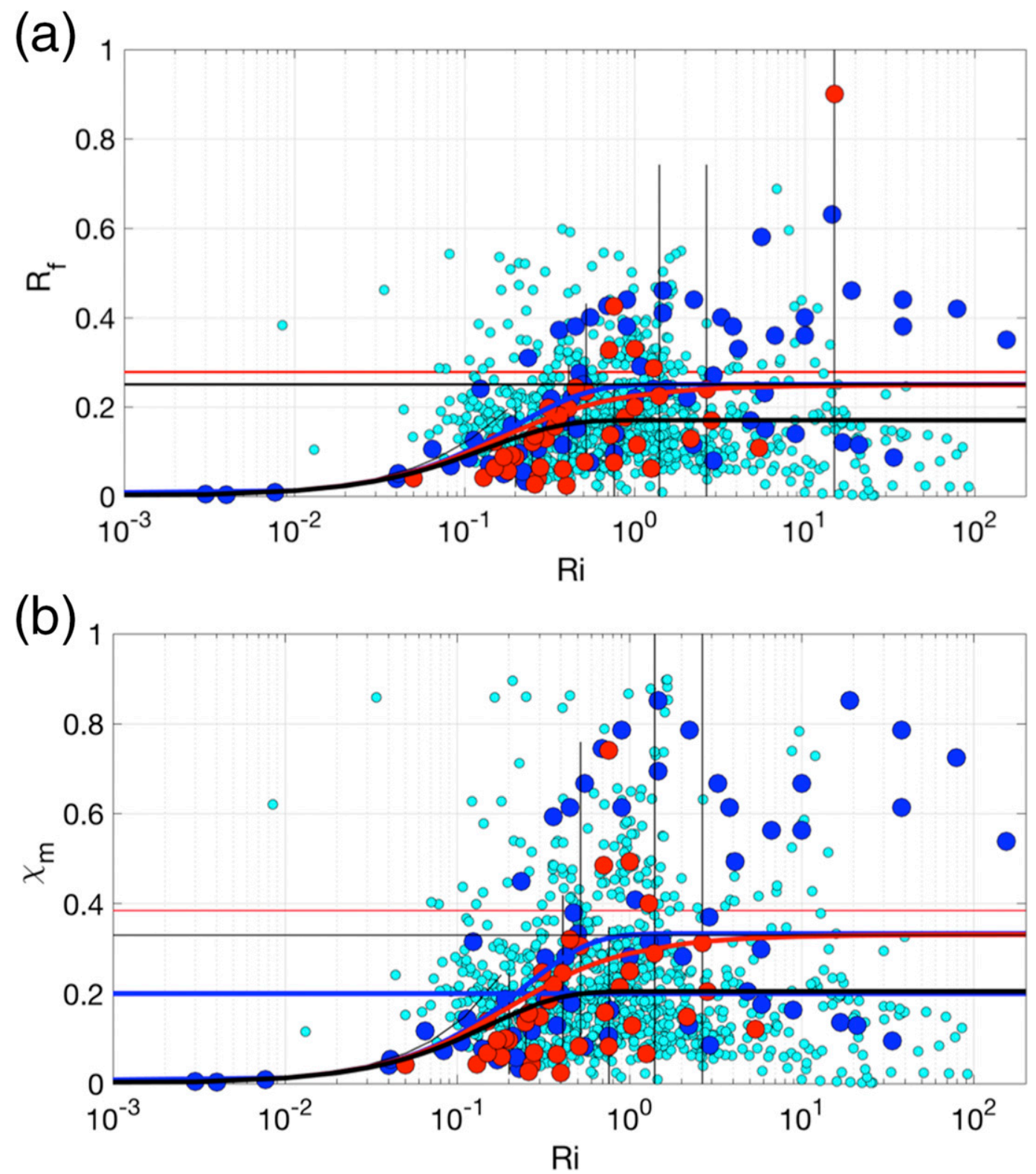

FIG. 7. As in Fig. 6, but the (a) flux Richardson number and (b) mixing coefficient are plotted against the gradient Richardson number (see text for details).

number is around 0.8. Equations (53) and (54) do not have the proper asymptotic behavior as $\mathrm{Ri} \rightarrow 0$, whereas Eq. (35) (thick blue line) does:

$$
\operatorname{Pr}_{t} \rightarrow \operatorname{Pr}_{t}^{0}<1 \quad \text { as } \quad \mathrm{Ri} \rightarrow 0 .
$$

The thick blue line in Figs. $6 a$ and $6 \mathrm{~b}$ corresponds to the semiempirical model of Eq. (36) with $R_{f}^{\max }=0.25$ and $\operatorname{Pr}_{t}^{0}=0.8$, whereas the thick black line corresponds to $R_{f}^{\max }=0.17$ and $\operatorname{Pr}_{t}^{0}=0.8$. These are close to the thick red line corresponding to theoretical results from the second-moment closure model of Kantha and Carniel (2009), thus confirming the good agreement between the two. The closure model of Kantha and Carniel (2009) is consistent with laboratory and field observations as well as with recent theoretical studies (Galperin et al. 2007) that indicate that turbulence can exist at Ri values as high as 200 .

Last, recall that the primary interest in studies involving measurements of the TKE dissipation rate, both in the ocean and the atmosphere, is in determining the scalar turbulent mixing coefficient in the fluid column through Eq. (20). This, of course, requires knowledge 
of mixing coefficient $\chi_{m}$ (equivalently $R_{f}$ ). For future reference, Figs. $7 \mathrm{a}$ and $7 \mathrm{~b}$ show $R_{f}$ and $\chi_{m}$ plotted against Ri. The observational data points are as in Figs. 6a and $6 \mathrm{~b}$. Once again, ShUREX observations are consistent with earlier studies.

It is worth pointing out that, while $R_{f}$ and $R i$ are independent measurements, from Eq. (31) $\mathrm{Pr}_{t}$ involves $\mathrm{Ri}$ and therefore there could be some self-correlation in the $\mathrm{Pr}_{t}$ and $1 / \mathrm{Pr}_{t}$ plots against Ri. Anderson (2009) made a study of this topic, but the relationship he recommends [his Eq. (16)] for the variation of $\operatorname{Pr}_{t}$ versus Ri, based on his analysis (not shown), gives values in poor agreement with data in Figs. 6a and 6b. He also assumes $\operatorname{Pr}_{t}$ at $\mathrm{Ri}=0$ is equal to 1.0. Using a more realistic value of around 0.8 , the agreement becomes worse. Nevertheless, the possibility of self-correlation should be kept in mind when interpreting inferred (and not directly measured) values of $\operatorname{Pr}_{t}$ in the oceans and the atmosphere. The possible effect of the differences in the molecular Prandtl number of air and water (Salehipour et al. 2015) should also be kept in mind.

Overall, the agreement between ShUREX data and earlier studies is very good, but scatter is still too large. The lack of collocation in time and space of UAV and radiosonde observations may have contributed to some but not all of the scatter observed in Figs. 6 and 7. Note also that some points fall beyond $\operatorname{Pr}_{t}=1$ and $\operatorname{Pr}_{t}=0$, both theoretically untenable. The same is true for some of the earlier studies. This goes to highlight the large uncertainty and hence error bars associated with difficult turbulence measurements such as these, whether in the oceans, the atmosphere, or the laboratory.

An important point to note in Figs. 6 and 7 is that the thick black line corresponding to the semiempirical model of Eqs. (36) and (35), respectively, but with $R_{f}^{\max }=0.17$ and $\operatorname{Pr}_{t}^{0}=0.8$, appears to agree better with data from both ShUREX and earlier studies for $\mathrm{Ri}$ values above approximately 0.1 . This is interesting, since an $R_{f}$ value of 0.17 corresponds to a $\chi_{m}$ value of 0.2 . The various universal constants that go into Kantha and Clayson's (2004) and Kantha and Carniel's (2009) models determine the values of both $R_{f}^{\max }$ and $\operatorname{Pr}_{t}^{0}$, and so this study indicates the need for perhaps reexamining one of those universal constants to reduce the value of $R_{f}^{\max }$ from the currently set value of 0.25 to 0.17 .

Last, it is important to remember that ultimately, a primary goal of turbulence models and measurements is to be able to better determine and utilize the mixing coefficients of momentum and heat (and scalar properties), $K_{M}$ and $K_{\theta}$, respectively, in the oceans and the atmosphere. These coefficients can be written in nondimensional form, using Eqs. (13), (20), (29), and (31), as

$$
\bar{K}_{M}=\frac{K_{M} N^{2}}{\varepsilon}=\frac{\mathrm{Ri}}{1-R_{f}} \quad \text { and } \quad \bar{K}_{H}=\frac{K_{\theta} N^{2}}{\varepsilon}=\frac{R_{f}}{1-R_{f}} .
$$

Because $R_{f}$ is a unique function of Ri (e.g., Kantha and Carniel 2009), both of these nondimensional coefficients are functions of $\mathrm{Ri}$ and only $\mathrm{Ri}$. In the oceans, the mixing coefficient $K_{M}$ can be deduced from microstructure measurements, provided that $\mathrm{Ri}$ is also measured simultaneously (mixing coefficient $K_{H}$ is obtained from simultaneous measurements of the dissipation rate of the temperature variance $\chi_{T}$ by the microstructure profiler). This once again highlights the importance of deploying ADCPs during microstructure measurements if $\mathrm{Ri}$ values cannot be obtained from the sensors deployed on the profiler. For UAV measurements in the atmosphere, on the other hand, it is important to be able to deduce ambient wind velocity as accurately as possible (currently still problematic) from measurements of velocities relative to the wind and the ground.

\section{Concluding remarks}

From measurements made over the past few decades, oceanographers have discovered that tracer experiments in the upper ocean show that an excellent agreement is obtained for tracer diffusion if the mixing coefficient $\chi_{m}$ is assumed to be 0.20 . However, theory requires that it be a function of the strength of stratification as indicated, for example, by the gradient Richardson number $\mathrm{Ri}$. The constant mixing coefficient producing good agreement with tracer studies in the ocean has puzzled oceanographers for decades [see the reviews by Peltier and Caulfield (2003); Gregg et al. (2018)]. ShUREX 2016 observations reported above are consistent with past studies in the oceans, the atmosphere, and the laboratory. The histogram of $\chi_{m}$ shows that the most likely value is about 0.16 , and use of the corresponding value of $\gamma$ in radar studies is a viable option, just like the use of $\chi_{m}=0.2$ provides acceptable diffusivities in the ocean.

It is well known that $\chi_{m}$ can have a value as high as 0.8 during the initial stages of Kelvin-Helmholtz instability before fully developed turbulence ensues and $\chi_{m}$ settles down to a value of about 0.2 (e.g., Peltier and Caulfield 2003). It is also well known that accurate measurements of diffusion and dissipation rates in stably stratified flows are difficult to make and that data points necessarily involve huge error bars, which are often not presented. Therefore, given the large scatter, the Ri dependence of $\chi_{m}$ is often obscured by the scatter (e.g., Fig. 7b), and a constant value can be taken as a reasonable fit to the data as long as $\mathrm{Ri}$ values exceed about 0.1 or so. It may be that 
Ri seldom falls below approximately 0.1 in the oceans and the atmosphere so that a value for $\chi_{m}$ of about 0.2 turns out to be a good approximation, all things considered. However, this is just speculation, and further studies and observations are essential to reinforce or refute it. We suggest that any future observations, whether in the oceans, the atmosphere, or the laboratory, include simultaneous measurements of Ri. This recommendation means that any future tracer studies in the ocean should also simultaneously measure prevailing $\mathrm{Ri}$ values. If it turns out that Ri seldom falls below approximately 0.1 but can reach values well above the canonical value of 0.25 , then the above speculation may be justifiable.

Acknowledgments. Authors LK and HL thank Professor D. Lawrence and Professor H. Hashiguchi for participation in the ShUREX campaigns organized by LK and for assisting in the analysis of the UAV data. The hospitality of RISH personnel and director Prof. Tsuda to their visitors is exemplary. The MU radar is operated by RISH.

\section{REFERENCES}

Abarbanel, H. D., D. Holm, J. E. Marsden, and T. Ratiu, 1984: Richardson number criterion for the nonlinear stability of three-dimensional stratified flow. Phys. Rev. Lett., 52, $2352-$ 2355, https://doi.org/10.1103/PhysRevLett.52.2352.

Alisse, J.-R., and C. Sidi, 2000: Experimental probability density functions of small-scale fluctuations in the stably stratified atmosphere. J. Fluid Mech., 402, 137-162, https://doi.org/ 10.1017/S0022112099006813.

_, P. H. Haynes, J. Vanneste, and C. Sidi, 2000: Quantification of stratospheric mixing from turbulence microstructure measurements. Geophys. Res. Lett., 27, 2621-2624, https://doi.org/ 10.1029/2000GL011386.

Anderson, P. S., 2009: Measurement of Prandtl number as a function of Richardson number avoiding self-correlation. Bound.-Layer Meteor., 131, 345-362, https://doi.org/10.1007/ s10546-009-9376-4.

Arneborg, L., 2002: Mixing efficiencies in patchy turbulence. J. Phys. Oceanogr., 32, 1496-1506, https://doi.org/10.1175/ 1520-0485(2002)032<1496:MEIPT > 2.0.CO;2.

Balsley, B. B., L. Kantha, and W. Colgan, 2010: On the use of slow ascent meter-scale sampling (SAMS) radiosondes for observing overturning events in the free atmosphere. J. Atmos. Oceanic Technol., 27, 766-775, https://doi.org/ 10.1175/2009JTECHA1310.1.

Bertin, F., J. Barat, and R. Wilson, 1997: Energy dissipation rates, eddy diffusivity, and the Prandtl number: An in situ experimental approach and its consequences on radar estimate of turbulence parameters. Radio Sci., 32, 791-804, https://doi.org/ 10.1029/96RS03691.

Blix, T. A., 1993: In-situ studies of turbulence and mixing: Problems and questions. Coupling Processes in the Lower and Middle Atmosphere, E. V. Thrane, T. A. Blix, and D. C. Fritts, Eds., NATO ASI Series C, Vol. 387, Kluwer Academic, 329-344.
— E. V. Thrane, and Ø. Andreassen, 1990: In situ measurements of the fine-scale structure and turbulence in the mesosphere and lower thermosphere by means of electrostatic positive ion probes. J. Geophys. Res., 95, 5533-5548, https://doi.org/10.1029/ JD095iD05p05533.

Businger, J. A., J. C. Wyngaard, Y. Izumi, and E. F. Bradley, 1971: Flux-profile relationships in the atmospheric surface layer. J. Atmos. Sci., 28, 181-189, https://doi.org/10.1175/1520-0469(1971) 028<0181:FPRITA $>2.0$. CO;2.

Canuto, V. M., Y. Cheng, A. M. Howard, and I. N. Esau, 2008: Stably stratified flows: A model with no Ri(cr). J. Phys. Oceanogr., 65, 2437-2447, https://doi.org/10.1175/2007JAS2470.1.

Carniel, S., L. H. Kantha, J. W. Book, M. Sclavo, and H. Prandke, 2012: Turbulence variability in the upper layers of the Southern Adriatic Sea under a variety of atmospheric forcing conditions. Cont. Shelf Res., 44, 39-56, https://doi.org/10.1016/j.csr.2011.01.003.

Crane, R. K., 1980: A review of radar observations of turbulence in the lower stratosphere. Radio Sci., 15, 177-193, https://doi.org/ 10.1029/RS015i002p00177.

Delage, D., R. Roca, F. Bertin, J. Delcourt, A. Crémieu, M. Massebeuf, R. Ney, and P. Van Velthoven, 1997: A consistency check of three radar methods for monitoring eddy diffusion and energy dissipation rates through the tropopause. Radio Sci., 32, 757-767, https://doi.org/10.1029/96RS03543.

Dole, J., R. Wilson, F. Dalaudier, and C. Sidi, 2001: Energetics of small scale turbulence in the lower stratosphere from high resolution radar measurements. Ann. Geophys., 19, 945-952, https://doi.org/10.5194/angeo-19-945-2001.

Fukao, S., T. Sato, T. Tsuda, S. Kato, K. Wakasugi, and T. Makihira, 1985a: The MU radar with an active phased array system: 1. Antenna and power amplifiers. Radio Sci., 20, 11551168, https://doi.org/10.1029/RS020i006p01155.

_ - T. Tsuda, T. Sato, S. Kato, K. Wakasugi, and T. Makihira, 1985b: The MU radar with an active phased array system: 2 . In-house equipment. Radio Sci., 20,1169-1176, https://doi.org/ 10.1029/RS020i006p01169.

- H. Luce, T. Mega, and M. Yamamoto, 2011: Extensive studies of large-amplitude Kelvin-Helmholtz billows in the lower atmosphere with VHF middle and upper atmosphere radar. Quart. J. Roy. Meteor. Soc., 137, 1019-1041, https:// doi.org/10.1002/qj.807.

Gage, K. S., J. L. Green, and T. E. VanZandt, 1980: Use of Doppler radar for the measurement of atmospheric turbulence parameters from intensity of clear-air echoes. Radio Sci., 15, 407-416, https://doi.org/10.1029/RS015i002p00407.

Galperin, B., S. Sukoriansky, and P. S. Anderson, 2007: On the critical Richardson number in stably stratified turbulence. Atmos. Sci. Lett., 8, 65-69, https://doi.org/10.1002/asl.153.

Gibson, C. H., 1980: Fossil temperature, salinity, and vorticity in the ocean. Marine Turbulence, J. Nihoul, Ed., Elsevier Oceanography Series, Vol. 28, Elsevier, 221-257.

Gossard, E. E., 1990: Radar research on the atmospheric boundary layer. Radar in Meteorology, D. Atlas, Ed., Amer. Meteor. Soc., 477-527.

, and R. G. Strauch, 1983: Radar Observations of Clear Air and Clouds. Elsevier, 280 pp.

— perature and velocity to atmospheric static stability-Application to radar and acoustic sounding. J. Climate Appl. Meteor., 26, 1021-1036, https://doi.org/10.1175/1520-0450(1987)026<1021: ROTVOT $>2.0 . \mathrm{CO} ; 2$.

— R. B. Chadwick, W. D. Neff, and K. P. Moran, 1982: The use of ground-based Doppler radars to measure gradients, fluxes 
and structure parameters in elevated layers. J. Appl. Meteor., 21, 211-226, https://doi.org/10.1175/1520-0450(1982)021<0211: TUOGBD $>2.0 . \mathrm{CO} ; 2$.

— — - T. R. Detman, and J. Gaynor, 1984: Capability of surface-based clear-air Doppler radar for monitoring meteorological structure of elevated layers. J. Climate Appl. Meteor., 23, 474-485, https://doi.org/10.1175/1520-0450(1984)023<0474: COSBCA $>2.0 . \mathrm{CO} ; 2$.

—, J. E. Gaynor, R. J. Zamora, and W. D. Neff, 1985: Finestructure of elevated stable layers observed by sounder and in situ tower sensors. J. Atmos. Sci., 42, 2156-2169, https://doi.org/ 10.1175/1520-0469(1985)042<2156:FOESLO > 2.0.CO;2.

Gregg, M. C., E. A. D’Asaro, J. J. Riley, and E. Kunze, 2018: Mixing efficiency in the ocean. Annu. Rev. Mar. Sci., 10, $443-$ 473, https://doi.org/10.1146/annurev-marine-121916-063643.

Hocking, W. K., 1985: Measurement of turbulent energy dissipation rates in the middle atmosphere by radar techniques: A review. Radio Sci., 20, 1403-1422, https://doi.org/10.1029/ RS020i006p01403.

1992: On the relationship between the strength of atmospheric radar backscatter and the intensity of atmospheric turbulence. Adv. Space Res., 12, 207-213, https://doi.org/10.1016/ 0273-1177(92)90468-D.

_ 1996: An assessment of the capabilities and limitations of radars in measurements of upper atmosphere turbulence. $A d v$. Space Res., 17, 37-47, https://doi.org/10.1016/0273-1177(95) 00728-W.

- 1999: The dynamical parameters of turbulence theory as they apply to middle atmosphere studies. Earth Planets Space, 51, 525-541, https://doi.org/10.1186/BF03353213.

_ , and K. L. Mu, 1997: Upper and middle tropospheric kinetic energy dissipation rates from measurements of $C_{n}^{2}$-Review of theories, in-situ investigations, and experimental studies using the Buckland Park atmospheric radar in Australia. J. Atmos. Sol.-Terr. Phys., 59, 1779-1803, https://doi.org/10.1016/S13646826(97)00020-5.

— J. Röttger, R. D. Palmer, P. B. Chilson, and T. Sato, 2016: Atmospheric Radar: Application and Science of MST Radars in the Earth's Mesosphere, Stratosphere, Troposphere, and Weakly Ionized Regions. Cambridge University Press, 838 pp.

Holleman, R., W. Geyer, and D. Ralston, 2016: Stratified turbulence and mixing efficiency in a salt wedge estuary. J. Phys. Oceanogr., 46, 1769-1783, https://doi.org/10.1175/JPO-D-15-0193.1.

Howard, L. N., 1961: Note on a paper of John W. Miles. J. Fluid Mech., 10, 509-512, https://doi.org/10.1017/S0022112061000317.

Ivey, G., and J. Imberger, 1991: On the nature of turbulence in a stratified fluid. Part I: The energetics of mixing. J. Phys. Oceanogr., 21, 650-658, https://doi.org/10.1175/1520-0485(1991) 021<0650:OTNOTI $>2.0$.CO;2.

Kantha, L., 2003: On an improved model of the turbulent PBL. J. Atmos. Sci., 60, 2239-2246, https://doi.org/10.1175/15200469(2003)060<2239:OAIMFT $>2.0$.CO;2.

— waves on mixing in the oceanic mixed layer. Ocean Modell., 6, 101-124, https://doi.org/10.1016/S1463-5003(02)00062-8.

— , and S. Carniel, 2009: A note on modeling mixing in stably stratified flows. J. Atmos. Sci., 66, 2501-2505, https://doi.org/ 10.1175/2009JAS3041.1.

,$- \ldots$, and M. Sclavo, 2011: A note on modeling double diffusive mixing in the global ocean. Ocean Modell., 36, 40-48, https://doi.org/10.1016/j.ocemod.2010.09.003.

- D. Dawrence, H. Luce, H. Hashiguchi, T. Tsuda, R. Wilson, T. Mixa, and M. Yabuki, 2017: Shigaraki UAV-Radar
Experiment (ShUREX): Overview of the campaign with some preliminary results. Prog. Earth Planet. Sci., 4, 19, https:// doi.org/10.1186/s40645-017-0133-x.

Kondo, J., O. Kanechika, and N. Yasuda, 1978: Heat and momentum transfers under strong stability in the atmospheric surface layer. J. Atmos. Sci., 35, 1012-1021, https://doi.org/ 10.1175/1520-0469(1978)035<1012:HAMTUS > 2.0.CO;2.

Kudo, A., 2013: The generation of turbulence below midlevel cloud bases: The effect of cooling due to sublimation of snow. J. Appl. Meteor. Climatol., 52, 819-833, https://doi.org/10.1175/ JAMC-D-12-0232.1.

— H. Huce, H. Hashiguchi, and R. Wilson, 2015: Convective instability underneath midlevel clouds: Comparisons between numerical simulations and VHF radar observations. J. Appl. Meteor. Climatol., 54, 2217-2227, https://doi.org/10.1175/JAMC-D-15-0101.1.

Lawrence, D. A., and B. B. Balsley, 2013: High-resolution atmospheric sensing of multiple atmospheric variables using the DataHawk small airborne measurement system. J. Atmos. Oceanic Technol., 30, 2352-2366, https://doi.org/10.1175/ JTECH-D-12-00089.1.

Ledwell, J., A. Watson, and C. Law, 1998: Mixing of a tracer in the pycnocline. J. Geophys. Res., 103, 21 499-21 529, https:// doi.org/10.1029/98JC01738.

—, E. Montgomery, K. Polzin, L. C. St. Laurent, R. Schmitt, and J. Toole, 2000: Evidence for enhanced mixing over rough topography in the abyssal ocean. Nature, 403, 179-182, https:// doi.org/10.1038/35003164.

— coastal environment: 1. A view from dye dispersion. J. Geophys. Res., 109, C10013, https://doi.org/10.1029/2003JC002194.

Li, L., W. D. Smyth, and S. A. Thorpe, 2015: Destabilization of stratified shear layer by ambient turbulence. J. Fluid Mech., 771, 1-15, https://doi.org/10.1017/jfm.2015.150.

Lilly, D. K., 1983: Stratified turbulence and the mesoscale variability of the atmosphere. J. Atmos. Sci., 40, 749-761, https:// doi.org/10.1175/1520-0469(1983)040<0749:STATMV>2.0.CO;2.

_ D. E. Waco, and S. I. Adelfang, 1974: Stratospheric mixing estimated from high-altitude turbulence measurements. J. Appl. Meteor., 13, 488-493, https://doi.org/10.1175/15200450(1974)013<0488:SMEFHA > 2.0.CO;2.

Lübken, F.-J., 1992: On the extraction of turbulent parameters from atmospheric density fluctuations. J. Geophys. Res., 97, 20385-20395, https://doi.org/10.1029/92JD01916.

—, U. Von Zahn, E. V. Thrane, T. Blix, G. A. Kokin, and S. V. Pachomov, 1987: In situ measurements of turbulent energy dissipation rates and eddy diffusion coefficients during MAP/ WINE. J. Atmos. Terr. Phys., 49, 763-775, https://doi.org/ 10.1016/0021-9169(87)90018-3.

Luce, H., L. Kantha, H. Hashiguchi, D. Lawrence, T. Mixa, M. Yabuki, and T. Tsuda, 2018: Vertical structure of the lower troposphere derived from MU radar, unmanned aerial vehicle, and balloon measurements during ShUREX 2015. Prog. Earth Planet. Sci., 5, 29, https://doi.org/10.1186/s40645-0180187-4.

Mack, S. A., and H. C. Schoeberlein, 2004: Richardson number and ocean mixing: Towed chain observations. J. Phys. Oceanogr., 34, 736-754, https://doi.org/10.1175/1520-0485(2004)034<0736: RNAOMT $>2.0 . \mathrm{CO} ; 2$.

McEwan, A. D., 1983: Internal mixing in stratified fluids. J. Fluid Mech., 128, 59-80, https://doi.org/10.1017/S0022112083000385.

Miles, J. W., 1961: On the stability of heterogeneous shear flows. J. Fluid Mech., 10, 496-508, https://doi.org/10.1017/ S0022112061000305. 
Ohya, Y., 2001: Wind-tunnel study of atmospheric stable boundary layers over a rough surface. Bound.-Layer Meteor., 98, 57-82, https://doi.org/10.1023/A:1018767829067.

Ottersten, H., 1969: Atmospheric structure and radar backscattering in clear air. Radio Sci., 4, 1179-1193, https://doi.org/ 10.1029/RS004i012p01179.

Peltier, W. R., and C. P. Caulfield, 2003: Mixing efficiency in stratified shear flows. Annu. Rev. Fluid Mech., 35, 135-167, https://doi.org/10.1146/annurev.fluid.35.101101.161144.

Peters, H., M. C. Gregg, and T. B. Sanford, 1995: Detail and scaling of turbulent overturns in the Pacific Equatorial Undercurrent. J. Geophys. Res., 100, 18349-18368, https://doi.org/10.1029/ 95JC01360.

Rehmann, C. R., and J. R. Koseff, 2004: Mean potential energy change in stratified grid turbulence. Dyn. Atmos. Oceans, 37, 271-294, https://doi.org/10.1016/j.dynatmoce.2003.09.001.

Rohr, J. J., and C. W. Van Atta, 1987: Mixing efficiency in stably stratified growing turbulence. J. Geophys. Res., 92, 5481-5488, https://doi.org/10.1029/JC092iC05p05481.

Salehipour, H., W. R. Peltier, and A. Mashayek, 2015: Turbulent diapycnal mixing in stratified shear flows: The influence of Prandtl number on mixing efficiency at high Reynolds number. J. Fluid Mech., 773, 178-223, https://doi.org/10.1017/ jfm.2015.225.

St. Laurent, L., and R. W. Schmitt, 1999: The contribution of salt fingers to vertical mixing in the North Atlantic Trace Release Experiment. J. Phys. Oceanogr., 29, 1404-1424, https://doi.org/10.1175/1520-0485(1999)029<1404:TCOSFT $>$ 2.0.CO;2.

Strang, E. J., and H. J. S. Fernando, 2001: Vertical mixing and transports through a stratified shear layer. J. Phys. Oceanogr., 31, 2026-2048, https://doi.org/10.1175/1520-0485(2001)031<2026: VMATTA $>2.0 . \mathrm{CO} ; 2$.

Stretch, D. D., J. W. Rottman, K. K. Nomura, and S. K. Venayagamoorthy, 2001: Transient mixing events in stably stratified turbulence. Proc. 14th Australasian Fluid Mechanics Conf., Adelaide, Australia, AFMC, 625-628.

Tatarskii, V. I., 1961: Wave Propagation in a Turbulent Medium. McGraw-Hill, 285 pp.

Taylor, J. R., 1992: The energetics of breaking events in a resonantly forced internal wave field. J. Fluid Mech., 239, 309-340, https://doi.org/10.1017/S0022112092004427.
Thorpe, S. A., 1973: Turbulence in stably stratified fluids: A review of laboratory experiments. Bound.-Layer Meteor., 5, 95-119, https://doi.org/10.1007/BF02188314.

_ W. W. Smyth, and L. Li, 2013: The effect of small viscosity and diffusivity on the marginal stability of stably stratified shear flows. J. Fluid Mech., 731, 461-476, https://doi.org/10.1017/ jfm.2013.378.

Thrane, E. V., and Coauthors, 1985: Neutral air turbulence in the upper atmosphere observed during the Energy Budget Campaign. J. Atmos. Terr. Phys., 47, 243-264, https://doi.org/10.1016/ 0021-9169(85)90136-9.

— , and Coauthors, 1987: Small scale structure and turbulence in the mesosphere and lower thermosphere at high latitudes in winter. J. Atmos. Terr. Phys., 49, 751-762, https://doi.org/ 10.1016/0021-9169(87)90017-1.

Tsuda, T., 2014: Characteristics of atmospheric gravity waves observed using the MU (Middle and Upper Atmosphere) radar and GPS (global positioning system) radio occultation. Proc. Japan Acad., 90B, 12-27, https://doi.org/10.2183/pjab.90.12.

VanZandt, T. E., J. L. Green, K. S. Gage, and W. L. Clark, 1978: Vertical profiles of refractivity turbulence structure constant: Comparison of observations by the Sunset Radar with a new theoretical model. Radio Sci., 13, 819-829, https://doi.org/ 10.1029/RS013i005p00819.

— K. S. Gage, and J. M. Warnock, 1981: An improved model for the calculation of profiles of $C_{n}^{2}$ and $\varepsilon$ in the free atmosphere from background profiles of wind, temperature, and humidity. 20th Conf. on Radar Meteorology, Boston, MA, Amer. Meteor. Soc., 129-135.

Wilson, R., F. Dalaudier, and F. Bertin, 2005: Estimation of the turbulent fraction in the free atmosphere from MST radar measurements. J. Atmos. Oceanic Technol., 22, 1326-1339, https://doi.org/10.1175/JTECH1783.1.

Zilitinkevich, S., T. Elperin, N. Kleeorin, and I. Rogachevskii, 2007: Energy and flux-budget (EFB) turbulence closure model for the stably stratified flows. Part I: Steady-state, homogeneous regimes. Bound.-Layer Meteor., 125, 167-191, https:// doi.org/10.1007/s10546-007-9189-2.

, I. N. Esau, T. Mauritsen, and M. W. Miles, 2008: Turbulence energetics in stably stratified geophysical flows: Strong and weak mixing regimes. Quart. J. Roy. Meteor. Soc., 134, 793-799, https://doi.org/10.1002/qj.264. 